\title{
Effects of natural polyphenol-rich pomegranate juice supplementation on plasma ion and lipid profiles following resistance exercise: a placebo-controlled trial
}

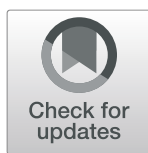

Achraf Ammar ${ }^{1,2^{*}}$, Khaled Trabelsi ${ }^{3,4}$, Stephen J. Bailey ${ }^{5}$, Mouna Turki ${ }^{6}$, Nicola Luigi Bragazzi ${ }^{7,8}$, Omar Boukhris ${ }^{3,9}$, Kais El Abed ${ }^{3}$, Mohamed Bouaziz ${ }^{10}$, Fatma Ayadi ${ }^{6}$, Tarak Driss ${ }^{11}$, Nizar Souissi ${ }^{9}$, Hamdi Chtourou ${ }^{3,9}$ and Anita Hökelmann ${ }^{1}$

\begin{abstract}
Background: Pomegranate juice (POMj) contains abundant soluble polyphenolic antioxidant compounds and is recommended for its cardioprotective/atheroprotective properties. However, very few studies have investigated the efficacy of POMj supplementation to alter physiological responses during intensive physical exercise. This placebocontrolled study aimed to examine whether supplementation with natural polyphenol-rich-POMj could influence the ionic or lipid responses to an intensive resistance training session in elite athletes.

Methods: Nine elite weightlifters ( $21 \pm 1$ years) performed two Olympic-weightlifting sessions after ingesting placebo and POMj supplements. Venous blood samples were collected at rest and 3 min after each session for assessment of plasma sodium $\left(\left[\mathrm{Na}^{+}\right]\right)$, potassium $\left(\left[\mathrm{K}^{+}\right]\right)$, chloride $\left(\left[\mathrm{Cl}^{-}\right]\right)$, calcium $\left(\left[\mathrm{Ca}^{2+}\right]\right)$, triglyceride $([\mathrm{TG}])$ and highdensity lipoprotein $([\mathrm{HDL}-\mathrm{C}])$, low-density lipoprotein $([\mathrm{HDL}-\mathrm{C}])$ and total $([\mathrm{TC}])$ cholesterol concentrations.

Results: Plasma $\left[\mathrm{K}^{+}\right]$and $[\mathrm{TG}]$ were lowered post-exercise compared to resting values in the PLA condition ( $p=0.03$ for $\mathrm{K}^{+}$and $p=0.02$ for TG) with no pre-to-post exercise differences in the other plasma ion and lipid markers ( $p$ > 0.05). Compared to rest, plasma $\left[\mathrm{Na}^{+}\right]$and $\left[\mathrm{Cl}^{-}\right]$were increased $\left(p=0.04, \%\right.$ change $=4.10 \%$ for $\mathrm{Na}^{+}$and $p=0.02$, \%change $=4.44 \%$ for $\mathrm{Cl}^{-}$), but there were no differences in the other plasma ion or lipid markers post-exercise after POMj supplementation ( $p>0$.05). Post-exercise plasma $\left[\mathrm{Na}^{+}\right],\left[\mathrm{Cl}^{-}\right]$, and $[\mathrm{HDL}-\mathrm{C}]$ were greater following POMj supplementation compared to PLA ( $p=0.01$ for $\mathrm{Cl}$ - and HDL-C, $p=0.02$ for $\mathrm{Na}+$, and $p=0.04$ for TC), with no between-supplement post-exercise differences in the other ion and lipid markers $(p>0.05)$.

(Continued on next page)
\end{abstract}

* Correspondence: ammar.achraf@ymail.com

${ }^{1}$ Institute of Sport Sciences, Otto-von-Guericke University, Magdeburg 39104, Germany

${ }^{2}$ Unit of Research Molecular Bases of Human Diseases, 12ES17, Faculty of

Medicine of Sfax, University of Sfax, Sfax 3000, Tunisia

Full list of author information is available at the end of the article

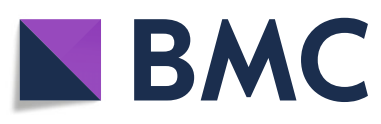

(c) The Author(s). 2020 Open Access This article is licensed under a Creative Commons Attribution 4.0 International License, which permits use, sharing, adaptation, distribution and reproduction in any medium or format, as long as you give appropriate credit to the original author(s) and the source, provide a link to the Creative Commons licence, and indicate if changes were made. The images or other third party material in this article are included in the article's Creative Commons licence, unless indicated otherwise in a credit line to the material. If material is not included in the article's Creative Commons licence and your intended use is not permitted by statutory regulation or exceeds the permitted use, you will need to obtain permission directly from the copyright holder. To view a copy of this licence, visit http://creativecommons.org/licenses/by/4.0/. The Creative Commons Public Domain Dedication waiver (http://creativecommons.org/publicdomain/zero/1.0/) applies to the data made available in this article, unless otherwise stated in a credit line to the data. 
(Continued from previous page)

Conclusion: In conclusion, supplementation with POMj has the potential to attenuate the acute imbalance of plasma $\left[\mathrm{K}^{+}\right]$and to improve blood lipid responses (i.e., HDL-C) following resistance exercises in elite weightlifters. However, further large research in both athletic and non-athletic populations is needed to corroborate these preliminary observations and to elucidate the potential underlying mechanisms and translational potential of our novel observations.

Trial registration: Name of the registry: ClinicalTrials.gov PRS

The registration number: NCT02697903.

Date of Registry: 03/03/2016 'Retrospectively registered'.

The registration title: Pomegranate Improve Biological Recovery Kinetics in Elite Weightlifter.

Keywords: Supplementation, Pomegranate juice, Physical exercise, Weightlifting

\section{Background}

Ions are positively (cations) or negatively (anions) charged molecules that are ubiquitous in the human body [1-3]. Proper electrolyte balance in the body is essential for normal functioning of cells, while alterations in electrolyte balance can impair cardiovascular and thermoregulatory functions [4]. With regard to exercise performance and post exercise recovery, sodium $\left(\mathrm{Na}^{+}\right)$, potassium $\left(\mathrm{K}^{+}\right)$, chloride $\left(\mathrm{Cl}^{-}\right)$, calcium $\left(\mathrm{Ca}^{2+}\right)$ and magnesium $\left(\mathrm{Mg}^{2+}\right)$ are the most important electrolytes [1, 4]. In the extracellular fluid, $\mathrm{Na}^{+}$is the primary cation and helps regulate acid base balance, nerve conduction, blood pressure, and muscle function $[1,5] . \mathrm{Cl}^{-}$is the primary anion and works in tandem with sodium to regulate nerve impulse conduction and body water balance [6]. In intracellular fluid, $\mathrm{K}^{+}$is the primary cation and helps maintain electrical activity in nerves, skeletal muscles, and the heart and also aids carbohydrate metabolism by enhancing glucose transport and glycogen storage $[7,8] . \mathrm{Ca}^{2+}$ and $\mathrm{Mg}^{2+}$ are cationic electrolytes that play important roles in the regulation of muscle contraction and enzymatic reactions [9-11]. In order to maintain skeletal muscle contractility and force production during exercise, the concentrations of several ions (i.e., $\mathrm{Na}^{+}, \mathrm{K}^{+}, \mathrm{Cl}^{-}, \mathrm{Ca}^{2+}$ ) change simultaneously in interstitial, transverse tubular and intracellular compartments $[1,12,13]$.

Although, these acute ionic adjustments are obligatory for the contraction of skeletal muscle, the development of ionic imbalances during repeated skeletal muscle contractions is implicated in the process of skeletal muscle fatigue $[1,5,9]$. Indeed, a diminished trans-sarcolemmal $\mathrm{K}^{+}$gradient coupled with lowered $\mathrm{Na}^{+}, \mathrm{Ca}^{2+}$ and $\mathrm{Cl}^{-}$ gradients can impair force production and cause fatigue [13]. Maintenance of ion homeostasis is, therefore, integral for optimizing skeletal muscle function, exercise performance and post-exercise recovery.

Previous studies investigating plasma ion responses following prolonged, high-intensity exercise (e.g., soccer) or exercise in the heat have reported slight to significant hyper- or hypokaliemia (high- or low $\left[\mathrm{K}^{+}\right]$) and slight to significant hyper- or hyponatremia (high- or low or $\left.\left[\mathrm{Na}^{+}\right]\right)[2,14-17]$. Discrepancies between findings might be linked to the configuration of the exercise protocol administered (e.g., intensity and duration) $[14,15,18]$, with high intensity (e.g., sprint, cycling) [2, 7] and/or more prolonged exercise (e.g., $100 \mathrm{~km}$ run, marathon, prolonged submaximal cycling) $[15,16]$ resulting in greater blood ion imbalances (e.g., Hyper- kaliemia or natremia). Indeed, in response to short duration moderate exercise (45 min), Emenike et al. [17] showed only a slight reduction in serum $[\mathrm{K}+]$ and $[\mathrm{Na}+]$, while short maximal isokinetic cycle ergometer exercise [2] and prolonged submaximal-cycling [15] or moderate-running [16] exercise were associated with significant increases in plasma $[\mathrm{K}+]$ and $[\mathrm{Na}+]$. These pronounced increases in plasma $[\mathrm{K}+]$ and $[\mathrm{Na}+]$ following prolonged and/or intensive exercises have been suggested to be due to the higher loss of fluids (via sweat) during prolonged exercise and to the inactivation of some $\mathrm{Na}^{+}-\mathrm{K}^{+}$-ATPase pumps, which play a crucial role in stabilizing $\mathrm{Na}+$ and $\mathrm{K}+$ concentration gradients and membrane excitability) during intense contractions [19]. However, although resistance exercise (e.g., weightlifting) is clearly classified as high-intensity physical exercise [20-26], there is a dearth of available studies addressing potential ionic imbalances during such exercise, and the existing evidence is conflicting [16, 17].

Physical exercise is also known to bring about changes in the blood lipid profile [27]. In term of improving athlete's cardiovascular health, an increase in high-density lipoprotein cholesterol (HDL-C), and reductions in lowdensity lipoprotein cholesterol (LDL-C), triglycerides (TG) and total cholesterol (TC) are classified as favorable post-exercise changes [28]. Nevertheless, such favorable alterations in blood lipid profile after a single session of exercise is not always observed [29, 30]. The available studies regarding the acute effect of physical exercise on plasma lipid profile have especially focused on prolonged aerobic based exercise and showed 
contradictory findings (i.e., decrease in LDL and increase in HDL $[31,32]$ vs. no change in both biomarkers [28, $33])$. Only two studies [14, 34] have been conducted to evaluate the influence of acute resistance exercise on post-exercise blood lipid profile and reported equivocal findings with a favorable increase of HDL-C registered only in the study of Hill et al. [34]. Therefore, given that lipid profile as well as plasma electrolytes responses are not yet established during intensive resistance exercises, it seems appropriate to investigate whether intensive weightlifting training-session can impair plasmatic electrolyte and lipids balance in elite athletes.

There is emerging evidence to suggest that dietary supplementation with food products rich in polyphenols might improve cardiometabolic risk factors such as hypertension and the lipid profile [35-38]. For example, pomegranate juice $(\mathrm{POMj})$ contains abundant soluble polyphenolic antioxidant compounds and is recommended as a dietary intervention to confer cardioprotective / atheroprotective effects, including lowering TC and inhibiting LDL oxidation [37, 38]. Indeed, the anthocyanin- and ellagitannin-active constituents of POMj can protect LDL against cell-mediated oxidation via the scavenging of reactive oxygen and nitrogen species or through their accumulation in arterial macrophages $[15,39]$. Moreover, since $\mathrm{Na}^{+}-\mathrm{K}^{+}$-ATPase pump [15] and $\mathrm{Ca}^{2+}$-ATPase pump [40] activity can be compromised by oxidative stress, $\mathrm{POMj}$ supplementation might blunt the ionic imbalances that develop during high-intensity exercise.

The purpose of the current study was to assess the effect of POMj supplementation on blood ions and lipid profiles following a resistance exercise training session. It was hypothesized that high-intensity resistance exercise would elicit blood ionic imbalances and positively modulate the blood lipid profile, and that POMj supplementation would abate blood ionic imbalances and promote further improvements in the blood lipid profile compared to a placebo condition.

\section{Methods}

The authors confirm that all ongoing and related trials for this intervention are registered.

\section{Participants}

The sample size was calculated a priori, using procedures described by Beck [41] and the software $G^{*}$ Power [42]. Values for $\alpha$ were set at 0.05 and for power at 0.90. Based on the results of Beyer et al. [43] and Ammar et al. [25], effect sizes were estimated to be 0.53 (medium effect). To reach the desired power, data from at least eight participants were deemed to be sufficient to minimize the risk of incurring a type 2 statistical error.
Nine healthy elite male weightlifters participating in a regional or national team and competing at an international standard [age: $21 \pm 1$ years, weight: $80 \pm 10 \mathrm{~kg}$, height: $1.75 \pm 0.08 \mathrm{~m}, \mathrm{BMI}: 23.4 \pm 1.17$, one-repetition maximum (1RM) Clean \& Jerk: $150 \pm 7 \mathrm{~kg}, 1 \mathrm{RM}$ Snatch: $120 \pm 6 \mathrm{~kg}($ mean $\pm \mathrm{SD})]$ volunteered to participate in this study. Potential participants were initially screened through telephone interviews based on the following inclusion criteria: i) 18-26 years of age, ii) body mass index (BMI) less than $25 \mathrm{~kg} / \mathrm{m}^{2}$, iii) they trained at least six sessions per week with at least 5 years' experience of Olympic weightlifting and iv) they did not have any injury or any other health problems. Exclusion criteria included: i) diagnosis of any chronic metabolic disease such as type 2 diabetes or cardiovascular disease, ii) diagnosis of an auto-immune disease such as rheumatoid arthritis, lupus, or type 1 diabetes, liver disease and iii) the intake of any medications (e.g., antioxidant or antiinflammatory drugs) or dietary supplements (e.g., creatine, foods rich in antioxidants or polyphenols such as blueberries, coffee, tea, grapes, cherries, curcuma, red wine and dark chocolate) during the experimental period and for at least one month before the commencement of the study. After receiving a thorough explanation of the possible risks and discomforts associated with the experimental procedures, each participant provided written informed consent to take part in the experiment. The study was conducted according to the Declaration of Helsinki and the study's protocols and procedures were fully approved by the local ethics committee of the $\mathrm{CHU}$ Habib Bourguiba, university of Sfax, Tunisia, before the commencement of the assessments (identification code: 8/16). Additionally, all ongoing and related trials for this intervention were registered with Clinical Trials.gov (identification code: NCT02697903).

\section{Experimental design}

A non-randomized placebo-controlled design was adopted for this study (Fig. 1). Neither staff nor participants were informed about the names of the two drinks (POMj and placebo, PLA), and blinding was strictly maintained by emphasizing to both staff and participants that both drinks were health promoting and advocated as potentially performance enhancing by certain sports medicine experts.

One week before the start of the experimental period, the heaviest weight lifted in a single repetition (1-RM) was assessed for each participant in each Olympic movement (Fig. 1). 1-RM was determined in three trials interspersed by 5 min recovery after an ascending warm-up from 40 to $80 \%$ of the athlete's estimated maximum [26]. Thereafter, participants performed, as part of their habitual training-program (i.e., during the precompetitive period) to avoid any repeated bout effect, 


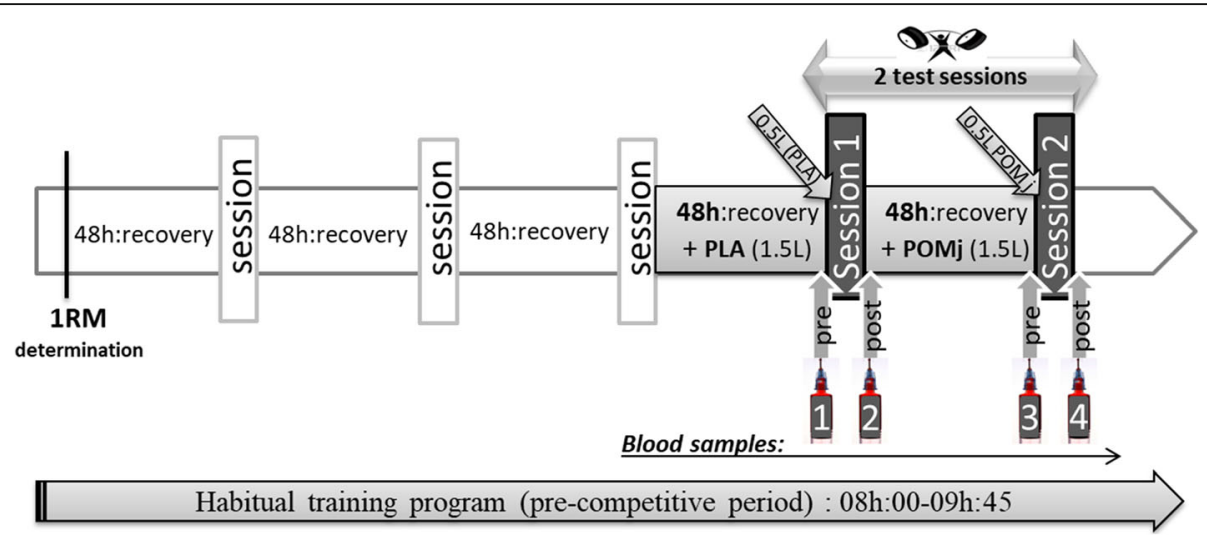

Fig. 1 Experimental design

two training sessions (Fig. 1) from 08:00 to 09:45 following the consumption of PLA and POMj with a $48 \mathrm{~h}$ washout between conditions [23, 25]. Before and $3 \mathrm{~min}$ after each training session, blood samples were collected (Fig. 1). Each resistance training session comprised three Olympic Weightlifting exercises: snatch, clean and jerk, and squat (performed in the same order for all participants and for both treatments) with 5 sets for each exercise and a total session duration of $1 \mathrm{~h} 46 \mathrm{~min}$. Specifically, participants completed 2 sets of 3 repetitions at $85 \%$ of $1-\mathrm{RM}$ and 3 sets of 2 repetitions at $90 \%$ of 1-RM. A passive recovery period of 5 and 8 min was administered between sets and the different OlympicWeightlifting exercises, respectively.

Participants consumed $250 \mathrm{~mL}$ of the PLA or POMj supplements three times daily (i.e., $07 \mathrm{~h}: 00,15 \mathrm{~h}: 00$ and $23 \mathrm{~h}: 00)$ over the $48 \mathrm{~h}$ that preceded the two training sessions. To ensure that each subject consumed the correct dose at the correct time point, subjects were contacted through a mobile telephone. Moreover, participants consumed an additional opaque and unmarked $500 \mathrm{~mL}$ can of PLA or POMj 60 min before commencing the training sessions to facilitate beneficial physiological effects [24]. Subjects were supervised by staff to ensure that they drank the entire quantity of fluid, and no exchange of bottles was allowed. Participants were instructed to drink the fluid quickly (within $1 \pm 0.5 \mathrm{~min}$ ) $60 \mathrm{~min}$ before their test session and not to discuss or compare tastes or to make any assumptions about what they had ingested. Consumption of POMj 60 min prior to training was chosen as this has been reported to be optimal for a complete polyphenol absorption, thereby favoring the attainment of peak polyphenol concentrations [24]. Beverages were prepared by an agrifood engineer. The natural POMj was prepared from a fresh pomegranate fruit $48 \mathrm{~h}$ before the beginning of the experimentation and was stored at $-4{ }^{\circ} \mathrm{C}$. No additional chemical products were added to the natural POMj.
PLA juice consisted of a pomegranate-flavored drink containing mineral water, natural identical flavor (pomegranate), stabilizers (Arabic-gum) with caloric sweeteners (i.e., added sugar) added to match the POMj energy content and avoid any confounding effect of different caloric content of the beverages [44]. The two drinks were similar in volume, texture, and appearance. One can of POMj (i.e., $500 \mathrm{~mL}$ ) contained $2.56 \mathrm{~g}$ of total polyphenols, $1.08 \mathrm{~g}$ of orthodiphenols, $292.6 \mathrm{mg}$ of flavonoids and $46.75 \mathrm{mg}$ of flavonols, $64 \mathrm{~g}$ of total carbohydrates (i.e., $56 \mathrm{~g}$ of sugar), and $1046 \mathrm{~kJ}$ of energy. The PLA drink (i.e., $500 \mathrm{~mL}$ ) did not contain antioxidants, vitamins or polyphenols, but comprised $60 \mathrm{~g}$ total carbohydrates (i.e., $54 \mathrm{~g}$ of added sugar), and $983 \mathrm{~kJ}$ of energy (Table 1). More details regarding the POMj processing $[22,45,46]$, phenolic extracts [47] and the determination of the total phenolic content $[48,49]$ can be found in supplementary materiel 1.

Before test sessions, participants underwent an overnight fast and were only permitted to drink one glass of water $(15-20 \mathrm{cL}$, depending on body mass: 0.22cL / Kg of body mass) in the morning to avoid the potential confounding influence of postprandial thermogenesis [50, 51].

Given that randomly assigning the supplements would have resulted in some participants consuming the POMj supplement before the PLA supplement, and since the beneficial effects of POMj could persist for up to three weeks after consumption [52], the authors elected to avoid any potential confounding effect of POMj supplementation altering blood biochemistry responses during the PLA condition by ensuring all participants completed the PLA condition first as recently suggested by Ammar et al. [24]. As the participants were elite weightlifters who were well trained and familiar with the exercises, and as the protocol (i.e., including both PLA and POMj conditions) was completed by all participants during the regular training program in the middle of the 
Table 1 Nutrition Facts of Pomegranate and Placebo Juices

\begin{tabular}{lll}
\hline Variables & Contents / 500 ml & \\
\cline { 2 - 3 } & POMj & PLA \\
\hline Total polyphenols (g) & 2,56 & 0 \\
Orthodiphenols (g) & 1,08 & 0 \\
Flavonoids (mg) & 292,6 & 0 \\
Flavonols (mg) & 46,75 & 0 \\
Calories & 250 & 235 \\
Calories from Fat & 0 & 0 \\
Total Fat (g) & 0 & 0 \\
Saturated Fat (g) & 0 & 0 \\
Trans Fat (g) & 0 & 0 \\
Cholestreol (mg) & 0 & 0 \\
Sodium (mg) & 15 & 12 \\
Potassium (mg) & 1270 & 4 \\
Calcium (mg) & 48 & 46 \\
Total Carbohydrate (g) & 64 & 60 \\
Dietery Fiber (g) & 0 & 0 \\
Sugars (g) & 56 & 54 \\
Protein (g) & $<1$ & 0 \\
Vitamin A (\%) & 0 & 0 \\
Vitamin C (\%) & 0 & 0 \\
Iron (\%) & & 0 \\
\hline
\end{tabular}

precompetitive period, the authors assume that an order effect is less likely to occurred. To avoid any time of day effects [20-22], all sessions were arranged in the morning hours.

\section{Dietary records}

To assess the adequacy of nutrient intake, a consecutive dietary record over the experimental period was completed. All participants received a detailed verbal explanation and written instructions on how to record their diet over the study period. Participants were asked to continue with their usual dietary habits during the period of dietary recording, but instructed to avoid antioxidant or anti-inflammatory drugs, and nutrients, foods or beverages rich in antioxidants, polyphenols or vitamins (e.g., blueberries, coffee, tea, grapes, cherries, curcuma, red wine and dark chocolate etc.). Indeed, a detailed list of such nutrients was given to all participants and they were asked to avoid consumption of such products from one month before experimentation and during the experimentation with a daily reminder via phone call during the experimental period. Additionally, participants were asked to be as accurate as possible in recording the amounts and types of food and fluid consumed. A list of common household measures, such as cups and tablespoons, and specific information about the quantity in each measurement (grams, etc.) were given to each participant. Each individual's dietary composition was calculated using the Bilnut 4 software package (SCDA Nutrisoft, Cerelles, France) and the food composition tables published by the Tunisian National Institute of Statistics in 1978.

\section{Blood sampling and analysis}

Blood samples $(7 \mathrm{~mL})$ were collected from a forearm vein at rest and $3 \mathrm{~min}$ following each training session in the PLA and POMj conditions. Samples were placed in an ice bath and immediately centrifuged at $3000 \mathrm{rpm}$ $1008 \mathrm{RCF}$ and $4{ }^{\circ} \mathrm{C}$ for $15 \mathrm{~min}$. Aliquots of the resulting plasma have been analyzed in the same day and in the same assay run to eliminate inter-assay-variance. All assays were performed in duplicate in the same laboratory with simultaneous use of a Multichem control serum. Levels of plasma ions and lipid profile parameters were determined spectrophotometrically (Architect Ci-4100ABBOTT, Abbott Deutschland, Wiesbaden, Germany) using the indirect potentiometric method for $\left[\mathrm{Na}^{+}\right],\left[\mathrm{K}^{+}\right]$ and $\left[\mathrm{Cl}^{-}\right]$, the single stable reagent (Arsenazo III) method for $\left[\mathrm{Ca}^{2+}\right]$, the enzymatic hydrolysis method by cholesterol esterase for [TC], the enzymatic hydrolysis and oxidation method by glycerol phosphate oxidase for [TG], and the enzymatic method by selective detergent for [HDL-C]. Plasma LDL-C contents have been estimated by Friedewald equation: $[\mathrm{LDL}-\mathrm{C}]=[\mathrm{TC}]-([\mathrm{HDL}-$ $\mathrm{C}]+[\mathrm{TG} / 2,2])$. Additionally, to account for any change in plasma volume shifts post exercise, hematological parameters [i.e., Red Blood Cells (RBC), Hemoglobin (HB), Hematocrit (HCT)] were assessed within $3 \mathrm{~h}$ in a multichannel automated blood cell analyzer (Beckman Coulter Gen system-2, Coulter T540, California, United States). As [HB] and [HCT] are highly sensitive to posture changes, all blood samples were collected in the sitting position after 5 min resting time for baseline (pre-exercise) samples and 3 min resting time for post exercises samples.

\section{Statistical analyses}

All statistical analyses were performed using STATISTICA 10.0 Software (StatSoft, Maisons-Alfort, France). Normality of the data distribution was confirmed using the Kolmogorov-Smirnov test $\left(p>0.2\right.$ for $\mathrm{Na}^{+}, \mathrm{K}^{+}, \mathrm{Cl}^{-}$, $\mathrm{Ca}_{2}{ }^{+}, \mathrm{TC}$, and TG, and $p=0.09$ for HDL-C and LDL-C). To analyze the effect of POMj supplementation on the plasma ions and lipid profile responses during training sessions (pre-post values), a two-way [supplement (PLA and $P O M j) \times$ time (pre and $3 \mathrm{~min}$ post training session)] ANOVA with repeated measures was employed. When significant effects were observed, Tukey's honestsignificance-difference (HSD) post-hoc tests were conducted. Effect sizes were calculated as partial eta-squared 
$\left(\eta_{\mathrm{p}}{ }^{2}\right)$ for the ANOVA analysis to interpret the magnitude of the change score using the following criteria: $<0.2=$ trivial, $0.2-0.6=$ small, $0.6-1.2=$ moderate, $1.2-2.0=$ large, $2.0-4.0=$ very large, and $>4.0=$ extremely large [53]. Statistical significance was set at $P<0.05$ and data are presented as mean \pm SD unless otherwise stated.

\section{Results}

\section{Dietary records}

Estimated nutrient intakes were referred to reference dietary intakes for physically active people and there were no differences in total calorie, macronutrient, and micronutrient intakes between the PLA and POMj conditions (Table 2).

\section{Hematological parameters cell count}

Compared with the baseline values, there was no significant changes in the hematological parameters in response to the resistance exercises in both PLA and POMj conditions (Table 3). Additionally, there was no significant differences between supplementation conditions at any of the time-points. Therefore, any observed changes in the blood parameters assessed (i.e., circulating ions and lipid profile) in response to the resistance exercises or POMj supplementation cannot be attributed to changes in hemoconcentration [54].

\section{Acute effect of POMj on plasma ions concentrations following a resistance training session}

Mean values for the blood ions (i.e., $\mathrm{Na}^{+}, \mathrm{K}^{+}, \mathrm{Cl}^{-}$and $\mathrm{Ca}^{2+}$ ) before and $3 \mathrm{~min}$ after the resistance training sessions (i.e., in the PLA and POMj conditions) are presented in Fig. 2. Statistical analysis showed a significant main effect of supplementation on $\left[\mathrm{Na}^{+}\right]\left(\mathrm{F}_{(1,8)}=5.57\right.$, $\left.p=0.04, \eta_{\mathrm{p}}{ }^{2}=0.41\right)$ and $\left[\mathrm{Cl}^{-}\right]\left(\mathrm{F}_{(1,8)}=6.37, p=0.03, \eta_{\mathrm{p}}{ }^{2}=\right.$ $0.44)$ with a significant increase pre-post training session only observed during the POMj condition (i.e., $p=$ 0.04 , \% change $=4.10 \pm 2.37 \%$ for $\left[\mathrm{Na}^{+}\right]$and $p=0.02$, \%

Table 2 Dietary record of the subjects (mean \pm SD)

\begin{tabular}{|c|c|c|}
\hline \multirow[t]{2}{*}{ Variables } & \multicolumn{2}{|l|}{ Mean \pm SD } \\
\hline & PLA testing days & POMj testing days \\
\hline Kilocalorie & $3269 \pm 485$ & $3254 \pm 510$ \\
\hline $\mathrm{CHO}(\%)$ & $53.63 \pm 5.6$ & $52.76 \pm 5.2$ \\
\hline Protein (\%) & $11.83 \pm 1.1$ & $12.37 \pm 1.3$ \\
\hline Fat (\%) & $27.09 \pm 4.0$ & $27.42 \pm 4.2$ \\
\hline Cholesterol (mg.day-1) & $326.1 \pm 97$ & $314.8 \pm 65$ \\
\hline Vit C (mg.day-1) & $45.33 \pm 11$ & $44.97 \pm 13$ \\
\hline Vit E (mg.day- 1) & $4.10 \pm 0.8$ & $4.07 \pm 0.6$ \\
\hline Vit A (ER) & $1300 \pm 252$ & $1280 \pm 189$ \\
\hline Folate $(\mu g \cdot d a y-1)$ & $335.6 \pm 53$ & $329.8 \pm 49$ \\
\hline Vit B12 ( $\mu \mathrm{g} \cdot$ day -1$)$ & $7.1 \pm 2.0$ & $6.9 \pm 1.9$ \\
\hline
\end{tabular}

Table 3 Hematological parameters before, immediately (3 min) and $48 \mathrm{~h}$ after the PLA and POMj resistance training sessions

\begin{tabular}{|c|c|c|c|c|}
\hline \multirow[t]{2}{*}{ Parameters } & \multicolumn{2}{|l|}{ PLA } & \multicolumn{2}{|l|}{ POMj } \\
\hline & Basal & $3 \mathrm{~min}$ & Basal & $3 \mathrm{~min}$ \\
\hline$R B C$ & 5.60 & 5.68 & 5.43 & 5.51 \\
\hline$\left(10^{6} / \mu l\right)$ & \pm 0.21 & \pm 0.18 & \pm 0.14 & \pm 0.20 \\
\hline Hemoglobin & 15.68 & 16.30 & 15.96 & 16.06 \\
\hline$(g / d l)$ & \pm 1.33 & \pm 1.95 & \pm 1.36 & \pm 1.49 \\
\hline Hematocrit & 48.53 & 48.94 & 47.71 & 48.19 \\
\hline (\%) & \pm 2.02 & \pm 2.57 & \pm 2.10 & \pm 2.36 \\
\hline
\end{tabular}

Placebo (PLA), Pomegranate juice (POMj) and Red Blood Cells ( $R B C)$

change $=4.44 \pm 2.03 \%$ for $\left.\left[\mathrm{Cl}^{-}\right]\right)$, resulting in higher postsession values of $\left[\mathrm{Na}^{+}\right]$and $\left[\mathrm{Cl}^{-}\right]$during the POMj condition compared to the PLA condition $(\mathrm{p}=0.02$ and $p=$ 0.01, respectively).

A significant main effect of time was observed for $\left[\mathrm{K}^{+}\right]$ $\left(\mathrm{F}_{(1,8)}=5.65, \mathrm{p}=0.04 \eta_{\mathrm{p}}{ }^{2}=0.41\right)$ with plasma $\left[\mathrm{K}^{+}\right]$significantly decreasing from pre-to-post- training session only during the PLA condition $(p=0.03, \%$, change $=-8.77 \pm$ $4.19 \%)$. However, there was no significant difference in plasma $\left[\mathrm{K}^{+}\right]$between conditions 3 min post training session $(p>0.05)$. Similarly, no significant effect of supplementation condition or time was observed for $\left[\mathrm{Ca}^{2+}\right]$ during the resistance training session $(\mathrm{p}>0.05)$.

\section{Acute effect of POMj on plasma lipid concentrations following a resistance training session}

Fig 3 shows the plasma lipid profile (i.e., TC, HDL-C, LDL-C and TG) at pre- and post-training session during both PLA and POMj conditions. A significant main effect of supplementation condition was found for HDL-C $\left(\mathrm{F}_{(1,8)}=6.85, \mathrm{p}=0.03, \eta_{\mathrm{p}}{ }^{2}=0.46\right)$ with higher values 3 min post-training session in the POMj compared to the PLA conditions $(p=0.01)$. A significant pre-post training session decrease was observed for TG during the PLA condition with $p=0.02$ and \% change $=-12.79 \pm 6.59 \%$. There was no significant main effect of supplementation condition on TC, TG or LDL-C ( $\mathrm{p}>0.05)$.

\section{Discussion}

The aim of the present study was to investigate the effect of POMj supplementation on the responses in blood ions and lipids following an acute high-intensity resistance training session. In the PLA condition, plasma $\left[\mathrm{K}^{+}\right]$ and [TG] were lower following the training session compared to resting baseline values. However, there were no pre-to-post-exercise differences in plasma $\left[\mathrm{K}^{+}\right]$and $[\mathrm{TG}]$ following POMj consumption, and post-exercise plasma $\left[\mathrm{Na}^{+}\right],\left[\mathrm{Cl}^{-}\right]$, and $[\mathrm{HDL}-\mathrm{C}]$ were greater following POMj supplementation compared to PLA supplementation. However, only limited ionic and lipid imbalance was evoked by resistance exercise in the current study as 


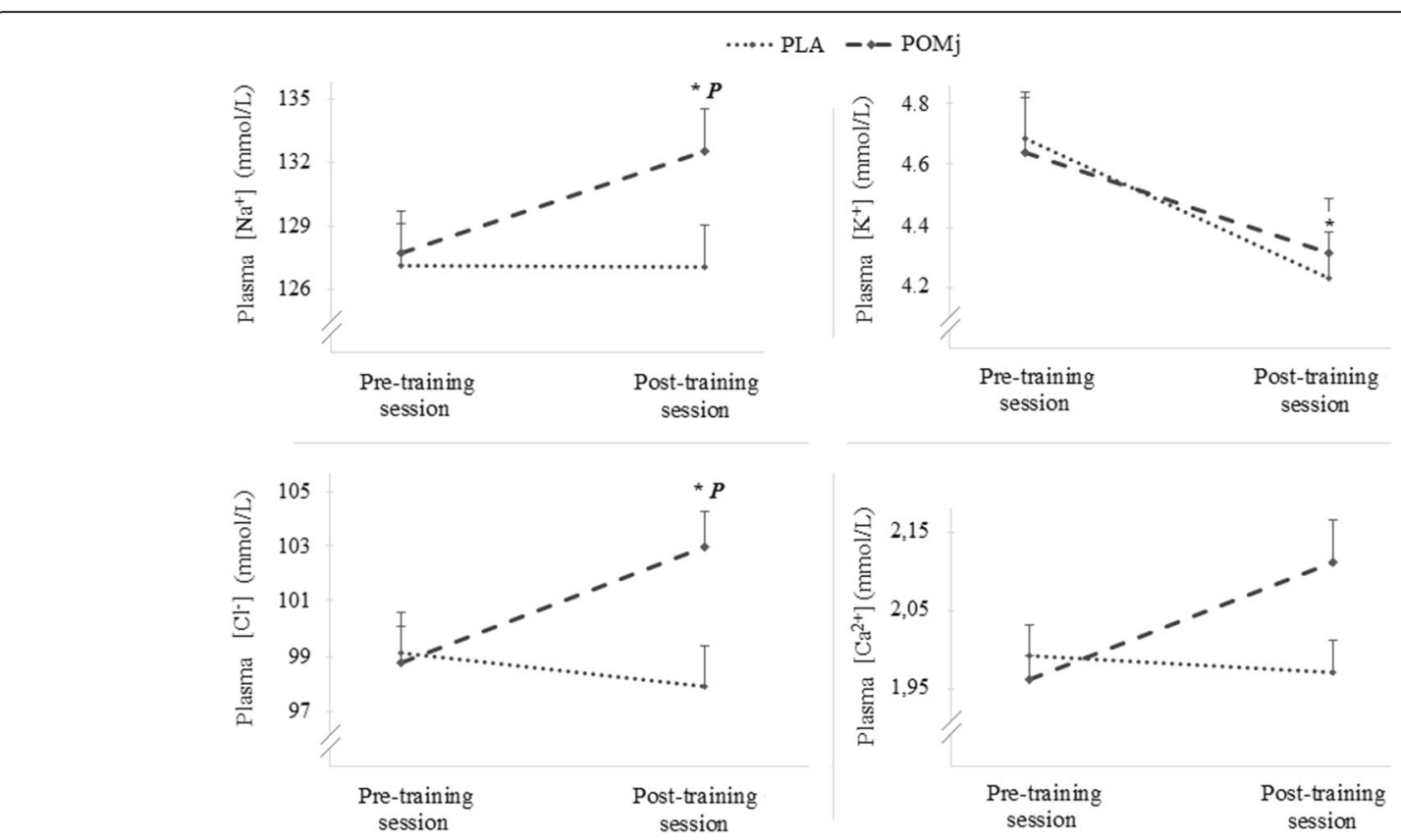

Fig. 2 Acute plasma ions in response to a resistance training session following POMj and PLA supplementation. *: Significant differences between pre- and 3 min post- training session with $p<0.05$. P: Significant difference between PLA and POMj condition with $p<0.05$. Placebo (PLA), Pomegranate juice (POMj), Sodium ( $\mathrm{Na}+)$, Potassium (K+), Chloride (Cl) and Calcium (Ca2+)

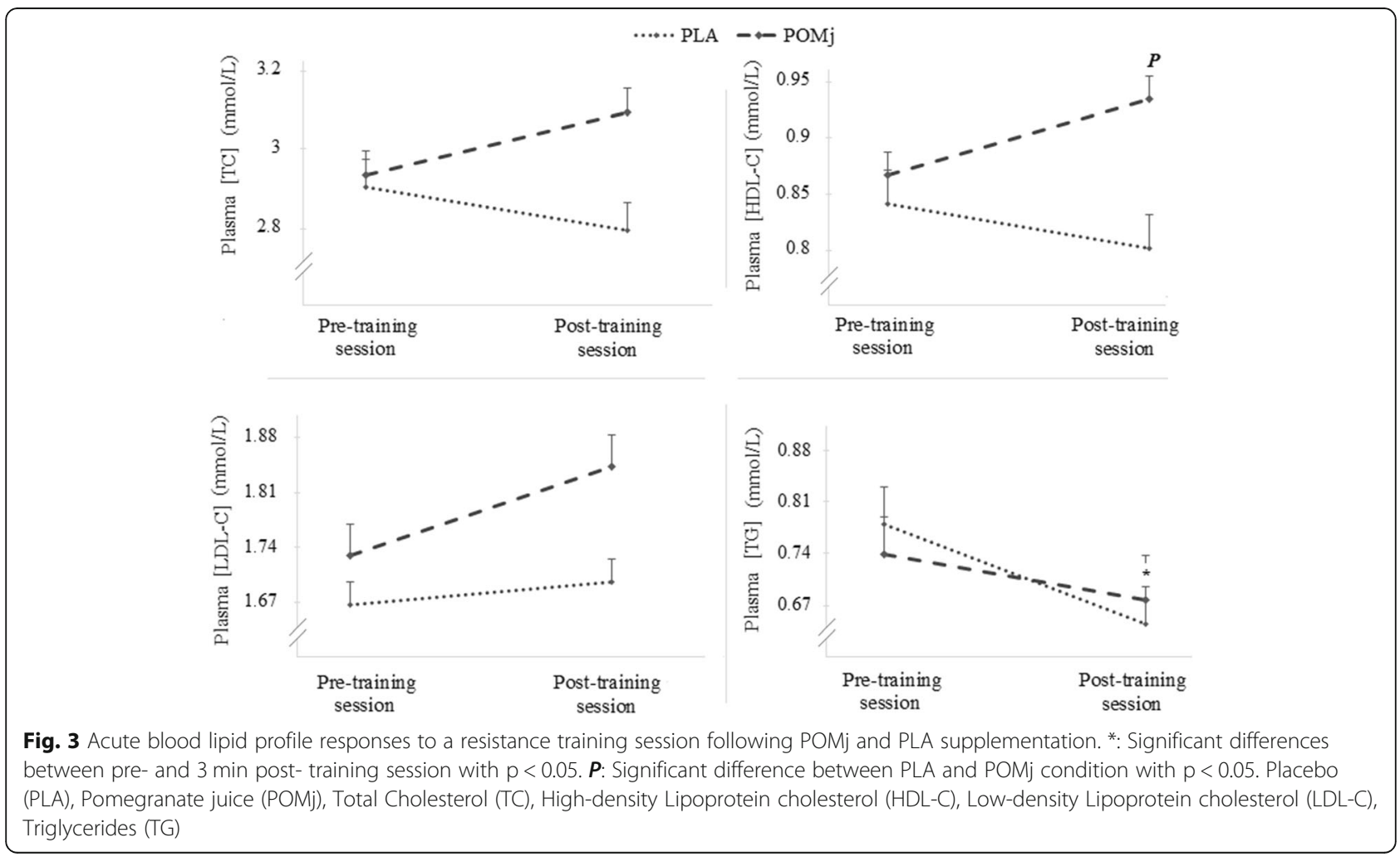


evidenced by alterations in some $\left(\mathrm{K}^{+}\right.$and $\left.\mathrm{TG}\right)$, but not all, ion and lipid markers. Since POMj supplementation only modulate post-exercise plasma $\left[\mathrm{Na}^{+}\right],\left[\mathrm{Cl}^{-}\right]$and [HDL-C] compared to PLA, the potential for POMj supplementation to improve resistance exercise performance and cardiometabolic health in trained athletes appears to be limited.

There is a strong body of evidence indicating that ionic imbalances during and following physical exercise is linked to the type of exercise administered and the environmental conditions [3, 12]. Following the highintensity resistance exercise completed in normothermic conditions in the present study, plasma $\left[\mathrm{K}^{+}\right]$was lower compared to baseline in the PLA condition. However, plasma $\left[\mathrm{Na}^{+}\right],\left[\mathrm{Ca}^{+}\right]$and $\left[\mathrm{Cl}^{-}\right]$were not altered after the high-intensity resistance exercise protocol in the PLA condition. The findings of the present study are in line with those of Emenike et al. [17] with regard $\left[\mathrm{K}^{+}\right]$, but conflicts with the observations from this study regarding $\left[\mathrm{Na}^{+}\right]$and $\left[\mathrm{Cl}^{-}\right]$responses. Indeed, the short duration exercise ( $45 \mathrm{~min}$ ) investigated by Emenike et al. [17] was associated with a slight reduction in serum $\left[\mathrm{K}^{+}\right],\left[\mathrm{Na}^{+}\right]$ and $\left[\mathrm{Cl}^{-}\right]$. Similarly, the present results conflict with numerous previous studies reporting increased plasma ions during $30 \mathrm{~s}$ maximal isokinetic cycle ergometer exercise (i.e., $\left[\mathrm{K}^{+}\right],\left[\mathrm{Na}^{+}\right]$and $\left.\left[\mathrm{Cl}^{-}\right],[2]\right)$, $90 \mathrm{~s}$ exhaustive intense knee-extensor exercise (i.e., $\left[\mathrm{K}^{+}\right]$, [55]) and prolonged submaximal-cycling (i.e., $\left[\mathrm{K}^{+}\right]$, $\left[\mathrm{Na}^{+}\right]$and $\left.\left[\mathrm{Ca}^{2+}\right],[15]\right)$ or moderate-running (i.e., $\left[\mathrm{K}^{+}\right]$and $\left[\mathrm{Na}^{+}\right],[16]$ ) exercise.

Previous reports have suggested that the inter-study discrepancies in plasma ion responses to physical exercise is linked to the configuration of the exercise protocol administered (e.g., intensity and duration) [14, 15, 18], with high intensity [15] and/or more prolonged exercise $[16,17]$ resulting in greater blood ion imbalances. However, the significant decrease of plasma $\left[\mathrm{K}^{+}\right]$and the absence of plasma $\left[\mathrm{Na}^{+}\right],\left[\mathrm{Ca}^{2+}\right]$ or $\left[\mathrm{Cl}^{-}\right]$alterations following the intensive long duration (1 h $46 \mathrm{~min})$ resistance session administered in the current study suggests that other factors are involved in mediating the ionic response to exercise. For example, the participant's training status could influence the effect of high-intensity exercise on plasma ionic responses. Indeed, increased plasma ion concentrations have been observed in studies investigating healthy habitually active $[2,15,55]$ or amateur subjects [16] while the attenuated ionic responses in the present study and in the study of Emenike et al. [17] have been observed in more highly trained participants. In this context, it has previously reported that well trained subjects undergo lower physiological (i.e., ionic imbalances, muscle damage, oxidative stress, inflammation etc) perturbations in responses to physical exercise [2, 20-26] due to the chronic adaptation of numerous physiological processes. Indeed, after 7 weeks of sprint training, McKenna et al. [2] showed that maximal exercise was accompanied by lower femoral arterial and venous plasma $\left[\mathrm{K}^{+}\right]$and $\left[\mathrm{Na}^{+}\right]$across all measurement times points (i.e., 0 to $10 \mathrm{~min}$ post exercises) compared to pre-training. These blunted changes in plasma $\left[\mathrm{K}^{+}\right]$ and $\left[\mathrm{Na}^{+}\right]$is likely the result of a greater activation of the muscle $\mathrm{Na}^{+} / \mathrm{K}^{+}$-pump.

With regard to skeletal muscle function, it was previously reported that acute ionic adjustments are obligatory to maintain skeletal muscle contractility and force production $[5,12,56]$. In this context, it was shown that the $\mathrm{Na}^{+} / \mathrm{K}^{+}$pump activity increases more than 20 -fold in order to maintain $\mathrm{Na}^{+}$and $\mathrm{K}^{+}$concentration gradients during exercise [12] with exercise-induced lactic acidosis increasing extra-cellular $\mathrm{Cl}^{-}$to help maintain skeletal muscle excitability [57]. However, during repeated skeletal muscle contractions (e.g., prolonged exercise) and/ or high intensity contraction, these adjustments can lead to the development of ionic imbalances which is implicated in the process of skeletal muscle fatigue and may adversely affect exercise performance $[1,5,9]$. In the present study, there were no alterations in the majority of the ions assessed (i.e., $[\mathrm{Na}+],[\mathrm{Cl}-]$ and $[\mathrm{Ca} 2+]$ ) between pre- and post-exercise in PLA condition during a single bout of high-intensity resistance exercise performed by elite athletes. This limited ionic imbalance is likely due to the high training status of the participants $([2,20-26])$ and suggests a limited role of ionic adjustment on exercise performance for this specific population in this context.

The administration of POMj in the present study blunted the decline in plasma $\left[\mathrm{K}^{+}\right]$and increased postexercise plasma $\left[\mathrm{Na}^{+}\right]$and $\left[\mathrm{Cl}^{-}\right]$compared to the PLA condition, but did not lead to hypernatremia $([\mathrm{Na}+]>$ $145 \mathrm{mmol} / \mathrm{l}$ [58]) abnormality. Although, the potential functional consequences of this effect are unclear, the higher plasma $\left[\mathrm{Cl}^{-}\right]$and the stabilization of $\left[\mathrm{K}^{+}\right]$response using POMj compared to PLA may suggest promising potential of POM supplementation in modulating muscle excitability, physical performance and post exercise fatigue. Indeed, increased sarcolemma $\mathrm{Cl}^{-}$permeability and extra-cellular $\mathrm{Cl}^{-}$levels has previously been shown to help maintain skeletal muscle excitability [57]. Likewise, maintained $\left[\mathrm{K}^{+}\right]$has been shown to (i) play a key role in maintaining muscle contraction during exercise by helping transport glucose into the muscle cells [5], (ii) interact with both $\mathrm{Na}^{+}$and $\mathrm{Cl}^{-}$to control fluid and ionic balances, and (iii) assist in the conduction of nerve impulse and muscle contractility $[8,12,59]$.

The mechanism underlying the effects of POMj supplementation on plasma ions during exercise remains to be elucidated [24]. However, it is acknowledged that the present attenuation in the decline in $\mathrm{K}^{+}$concentration from pre- to post- exercise using POMj compared to 
PLA could be explained by the higher $\mathrm{K}^{+}$content in the POMj used $(1.27 \mathrm{~g} / 500 \mathrm{ml})$ compared to PLA (only trace). Previous studies in health and disease have linked the observed ionic changes using POM consumption to the protective role of POM-polyphenols against reactive oxygen species (ROS)-induced inhibition of $\mathrm{Na}^{+} / \mathrm{K}^{+}$ pump activity in various tissues including brain, kidney and myocardium [60-62]. However, this potential beneficial effect of consuming POM-polyphenols on $\mathrm{Na}^{+} / \mathrm{K}^{+}$ pump activity has yet to be confirmed in skeletal muscle tissue following high-intensity exercise.

Concerning the lipid profile, in response to the investigated high-intensity resistance exercise, plasma [TG] declined post-exercise, with no change in plasma [TC], [HDL-C] or [LDL-C] compared to pre-exercise during the PLA condition. Previous studies focusing on the acute responses of blood lipid profile following strength exercises reported divergent findings with Lahiji et al. [28] showing no significant change in lipid profile immediately after one resistance exercise session, while a significant increase of HDL-C was immediately shown following a session with a similar training-volume but a higher intensity [34]. Discrepancies between these findings suggest that the lipid profile response to a single session of resistance exercise might be more influenced by exercise intensity [34]. Indeed, it has been recently suggested that intensive exercise may alter lipid profile by increasing expression of ATP-binding cassette transporter A-1 (ABCA1) in macrophages which has a strong effect on promoting the reverse cholesterol transport (RCT) pathway, plasma HDL-C formation, and protection against atherosclerosis [63]. The significant increase of [HDL-C] previously shown following intensive resistance exercises performed by a non-athlete population [28] and the attenuation of [TG] content among elite athlete population in the present study are in line with this suggestion.

Regarding the effect of POMj on lipid profile response, the significantly higher content of HDL-C at post training session following $\mathrm{POMj}$ supplementation compared to PLA confirm the potential improvement in cardiometabolic disease risk factors following POMj supplementation, as previously highlighted by Al-Dujaili et al. $[64,65]$ in healthy volunteers, and most importantly in vascular disease therapy [36, 38]. Indeed, in patients with both diabetes and hyperlipidemia, the administration of $40 \mathrm{~g}$ concentrated POMj for 8 weeks was shown to decrease [TC], [LDL-C], LDL-C/HDL-C ratio and TC/ HDL-C ratio [66]. Similarly, the administration of 200 $\mathrm{ml} /$ day POMj for 6 weeks, in patients with type 2 diabetes, decreased [TC] and [LDL-C] [38]. In relation to physical exercise, the present study is the first to test the potential of POMj supplementation to positively modulate the blood lipids profile following exercise. Previous studies in this field have only assessed the effect of POM supplementation on vascular function during different types of physical exercise [23-25, 67-69]. Indeed, POM supplementation has been reported to increase vessel diameter and blood flow, and to decrease systolic blood pressure and heart rate immediately following treadmill runs [67, 68], RSA test [69] and resistance exercises [63]. These beneficial effects of POMj have been linked to its abundant anti-oxidative polyphenolic compounds which are assumed to have cardioprotective effects [38, 70]. For example, POM polyphenols can protect LDL against cell-mediated oxidation by inhibiting macrophage lipid peroxidation $[15,39]$. Similarly, POM polyphenols were shown to have the potential to activate endothelial nitric oxide synthase (eNOS) [70, 71], and to attenuate ROSmediated nitric oxide scavenging [70], which is important given the vasodilatory properties of nitric [72]. Specifically, the higher post-exercise level of HDL-C following polyphenol-rich POMj consumption is likely due to the potential antioxidant effects conferred by its polyphenols content, leading to enhanced expression of genes related to HDL-C metabolism and function [73]. For example, by regulating cellular cholesterol efflux from macrophages and hepatic paraoxonase 1 expression and activity [74, 75]. In fact, previous clinical studies in a variety of human populations have shown that dietary polyphenol intake is associated with beneficial changes in serum biomarkers related to HDL function including increased HDL cholesterol concentration, as well as HDL antioxidant and cholesterol efflux capacities [75].

Taken together, these preliminary findings suggest a possible beneficial effect of dietary intake of natural polyphenol-rich POMj supplementation $(250 \mathrm{ml} \mathrm{POMj}$ $\times 3$ time daily) on some blood ion and lipid variables following high-intensity strength exercise in an athletic population. Although this modulation was limited to $\left[\mathrm{Na}^{+}\right],\left[\mathrm{Cl}^{-}\right]$and $[\mathrm{HDL}-\mathrm{C}]$, it might have beneficial implications for resistance exercise performance and post exercise recovery among athletic population. Indeed, using similar dietary supplementation, we previously demonstrated that POMj improved weightlifting performance (+ $3.3 \%$ for the maximal lifted amount and $+8.3 \%$ for the total lifted amount) and attenuated the perception of muscle fatigue $(-4.4 \%)$ and knee extensor muscle soreness (13.4\%) immediately and up to $48 \mathrm{~h}$ after a training session [25]. However, given that the resistance training session administered in the current study did not evoke significant ionic or lipid imbalance in the majority of the variables assessed, the improvement of resistance exercise performance previously shown in the same athletic population following POMj supplementation is unlikely to be due to improved maintenance of ionic or lipid balances, but more likely to other underlying mechanisms such as the attenuation of oxidative stress, muscle 
damage and inflammatory responses during and following exercise [23-25].

\section{Conclusion}

This study is the first to test the efficacy of POMj supplementation to modulate plasma ion and lipid profiles following high-intensity resistance exercise in elite athletes. Plasma $\left[\mathrm{K}^{+}\right]$and $[\mathrm{TG}]$ were lower following resistance exercise compared to resting baseline values in the PLA condition, but not the POMj condition. Postexercise plasma $\left[\mathrm{Na}^{+}\right],\left[\mathrm{Cl}^{-}\right]$and $[\mathrm{HDL}-\mathrm{C}]$ were greater following POMj supplementation compared to PLA supplementation. Therefore, POMj supplementation has the potential to modulate some blood ionic and lipid responses to resistance exercise. However, given the small sample size, and given that only a small number of variables were modulated using POMj, further research in both athletic and non-athletic populations is needed to corroborate these preliminary observations and to elucidate the potential underlying mechanisms and translational potential of our novel observations in the current study.

Ethics committee Local committee of the Laboratory of Biochemistry, CHU Habib Bourguiba, Sfax University, Tunisia.

Ethical registration number: 16/2015.

\begin{abstract}
Abbreviations
ABCA1: ATP-binding cassette transporter $\mathrm{A}-1 ; \mathrm{Ca}^{2+}$ : Calcium; $\mathrm{Cl}^{-}$: Chloride; eNOS: Endothelial nitric oxide synthase; $\eta^{2}$ : Eta squared; 1-RM: Heaviest weight lifted in a single repetition; HCT: Hematocrit; HB: Hemoglobin; HDLC: High-density lipoprotein; HSD: Honest-significance-difference; HDL-C: Lowdensity lipoprotein; $\mathrm{Mg}^{2+}$ : Magnesium; PLA: Placebo; POMj: Pomegranate juice; K+: Potassium; RBC: Red Blood Cells; RCT: Reverse cholesterol transport; $\mathrm{Na}^{+}$: Sodium; TC: Total cholesterol; TG: Triglyceride
\end{abstract}

\section{Acknowledgments}

The authors wish to thank all the participants for their maximal effort and cooperation.

The authors report no funding source for this work.

\section{Funding information}

The author(s) received no specific funding for this work.

\section{Authors' contributions}

Conceptualization: AA KT HC; Methodology: AA KT MT HC; Validation: AA NS HC AH; Formal analysis: AA MT FA; Investigation: AA KT HC; Data curation: AA MT HC FA HC; Writing (original draft preparation): AA; Writing (review and editing): KT, NLB, OB, KE, MB, NS, SJB, HC; Visualization: AA KT HC; Supervision: NS AH; Project administration: AA. The author(s) read and approved the final manuscript.

\section{Availability of data and materials}

The datasets analyzed during the current study are available from the corresponding author on reasonable request.

\section{Ethics approval and consent to participate}

The study's protocols and procedures were fully approved by the local ethics committee of the CHU Habib Bourguiba, university of Sfax, Tunisia, before the commencement of the assessments (identification code: 8/16). Additionally, all ongoing and related trials for this intervention were registered with Clinical Trials.gov (identification code: NCT02697903). Each participant provided written informed consent to take part in the experiment.

Consent for publication

Not applicable.

\section{Competing interests}

The authors declare that they have no competing interests.

\section{Author details}

${ }^{1}$ Institute of Sport Sciences, Otto-von-Guericke University, Magdeburg 39104, Germany. ${ }^{2}$ Unit of Research Molecular Bases of Human Diseases, 12ES17, Faculty of Medicine of Sfax, University of Sfax, Sfax 3000, Tunisia. ${ }^{3}$ High Institute of Sport and Physical Education, University of Sfax, Sfax 3000, Tunisia. ${ }^{4}$ Research Laboratory: Education, Motricité, Sport et Santé, EM2S, LR19JS01, High Institute of Sport and Physical Education of Sfax, University of Sfax, Sfax, Tunisia. ${ }^{5}$ School of Sport, Exercise and Health Sciences, Loughborough University, Loughborough LE11 3TU, UK. ' Laboratory of Biochemistry, CHU Habib Bourguiba, Sfax University, 3000 Sfax, Tunisia. 7Department of Health Sciences (DISSAL), Postgraduate School of Public Health, University of Genoa, Genoa 16132, Italy. ${ }^{8}$ Department of Mathematics and Statistics, Laboratory for Industrial and Applied Mathematics (LIAM), York University, Toronto, ON M3J 1P3, Canada. ${ }^{9}$ Activité Physique, Sport et Santé, UR18JS01, Observatoire National du Sport, Tunis 1003, Tunisia. ${ }^{10} \mathrm{High}$ Institute of Biotechnology, Sfax University, Sfax 3000, Tunisia.

${ }^{11}$ Interdisciplinary Laboratory in Neurosciences, Physiology and Psychology: Physical Activity, Health and Learning (LINP2-2APS), UFR STAPS, UPL, Paris Nanterre University, Nanterre 92000, France.

Received: 23 October 2019 Accepted: 6 April 2020

Published online: 16 April 2020

\section{References}

1. Armstrong LE, Epstein Y. Fluid-electrolyte balance during labour and exercise: concepts and misconceptions. Int J Sport Nutr. 1999;9:1-12..

2. McKenna MJ, Heigenhauser GJ, McKelvie RS, MacDougall JD, Jones NL. Sprint training enhances ionic regulation during intense exercise in men. J Physiol. 1997;501:687-702.

3. Senay LC. Relationship of Evaporative Rates to Serum [Na+], [K+],and Osmolarity in Acute Heat Stress. J Appl Physiol. 1968;25:149-52.

4. Ziegenfuss TN, Landis J, Willoughby D, Greenwood M. Nutritional Supplements to Enhance Recovery. In: Greenwood M, Cooke M, Ziegenfuss T, Kalman D, Antonio J. (eds) Nutritional Supplements in Sports and Exercise. Cham: Springer; 2015.

5. McKenna MJ, Bangsbo J, Renaud JM. Muscle K+, $\mathrm{Na}+$, and cl disturbances and $\mathrm{Na}+-\mathrm{K}+$ pump inactivation: implications for fatigue. J Appl Physiol. 2007;104:288-95.

6. Pedersen $\mathrm{TH}$. Evidence for a role of $\mathrm{Cl}^{-}$conductance in the protective effect of lactic acid on the excitability in muscles at high $[K+]$. Acta Physiol Scand. 2004;181:R153.

7. Medbo Jl, Sejersted OM. Plasma potassium changes with high intensity exercise. J Physiol. 1990;421:105-22.

8. Palmer BF. Regulation of potassium homeostasis. Clin J Am Soc Nephrol. 2014;10:1050-60.

9. Allen $\mathrm{DG}$, Lamb $\mathrm{GD}$, Westerblad $\mathrm{H}$. Impaired calcium release during fatigue. J Appl Physiol (1985). 2008;104(1):296-305.

10. Lin LL, Hsieh SS. Effects of strength and endurance exercise on calciumregulating hormones between different levels of physical activity. J Mech Med Biol. 2005;05(02):267-75.

11. Stokes DL, Wagenknecht T. Calcium transport across the sarcoplasmic reticulum: structure and function of Ca2+-ATPase and the ryanodine receptor. Eur J Biochem. 2000;267(17):5274-9.

12. Clausen $\mathrm{T}$. Role of $\mathrm{Na}+, \mathrm{K}+$-pumps and transmembrane $\mathrm{Na}+, \mathrm{K}+$-distribution in muscle function. The FEPS lecture - Bratislava 2007. Acta Physiol. 2008; 192:339-49.

13. Cairns SP, Lindinger MI. Do multiple ionic interactions contribute to skeletal muscle fatigue? J Physiol. 2008;586(17):4039-54. https://doi.org/10.1113/ jphysiol.2008.155424.

14. Maimoun L, Simar D, Malatesta D, Cailand C, Peruchou E, Couret J, et al. Response of bone metabolism related hormones to a single session of 
Strenous exercise in active elderly subjects. Br J Sports Med. 2005;39:497502.

15. Aviram M, Rosenblat M, Gaitini D, Nitecki S, Hoffman A, Dornfeld L, et al. Pomegranate juice consumption for 3 years by patients with carotid artery stenosis reduces common carotid intima-media thickness, blood pressure and LDL oxidation. Clin Nutr. 2004:23:423-33.

16. Wołyniec W, Ratkowski W, Kasprowicz K, Małgorzewicz S, Aleksandrowicz E, Witek K, et al. Changes in electrolytes and uric acid excretion during and after a 100 km run. J Biol Regul Homeost Agents. 2018;32:1205-10.

17. Emenike US, Ifeanyi OE, Chinedum OK, Okechukwu OR, Chineneye AS. Effect of physical exercises on serum electrolyte. IOSR-JDMS. 2014;13:118-21.

18. Nielsen $\mathrm{OB}$, de Paoli F, Overgaard K. Protective effects of lactic acid on force production in rat skeletal muscle. J Physiol. 2001;536:161-6.

19. McKenna MJ, Bangsbo J, Renaud JM. Muscle K+, Nat, and Cl disturbances and $\mathrm{Na}+-\mathrm{K}+$ pump inactivation: implications for fatigue. J Appl Physiol (1985). 2008;104(1):288-95.

20. Ammar A, Chtourou H, Hammouda O, Trabelsi K, Chiboub J, Turki M, et al. Acute and delayed responses of C-reactive protein, malondialdehyde and antioxidant markers after resistance training session in elite weightlifters: effect of time of day. Chronobiol Int. 2015;32:1211-22.

21. Ammar A, Chtourou H, Souissi N. Effect of time-of-day on biochemical markers in response to physical exercise. J Strength Cond Res. 2017;31:27282.

22. Ammar A, Chtourou H, Hammouda O, Turki M, Ayedi F, Kallel C, et al. Relationship between biomarkers of muscle damage and redox status in response to a weightlifting training session: effect of time-of-day. Physiol Int. 2016:103:243-61.

23. Ammar A, Turki M, Hammouda O, Chtourou H, Trabelsi K, Bouaziz M, et al. Effects of pomegranate juice supplementation on oxidative stress biomarkers following weightlifting exercise. Nutrients. 2017;9:819.

24. Ammar A, Bailey SJ, Chtourou H, Trabelsi K, Turki M, Hökelmann A, et al. Effects of pomegranate supplementation on exercise performance and post-exercise recovery: a systematic review. Br J Nutr. 2018;20:1201-16.

25. Ammar A, Turki M, Chtourou H, Hammouda O, Trabelsi K, Kallel C, et al. Pomegranate supplementation accelerates recovery of muscle damage and soreness and inflammatory markers after a weightlifting training session. PLoS One. 2016;11:e0160305.

26. Ammar A, Chtourou H, Trabelsi K, Padulo J, Turki M, El Abed K, et al. Temporal specificity of training: intra-day effects on biochemical responses and Olympic-weightlifting performances. J Sports Sci. 2015;33:358-68.

27. Boraita A. Plasma lipid profile is improved by participation in sports, but at what Intensivity? Rev Esp Cardiol. 2004;57:495-8.

28. Lahiji F, Vasaghi Gharamaleki B, Mirzaii Dizgah I, Abdollahi A, Attarbashi MB. The effect of a single session of aerobic or resistance exercise on salivary lipid profile. J Arch Mil Med. 2015;3:e26341.

29. Thompson PD, Crouse SF, Goodpaster B, Kelley D, Moyna N, Pescatello L. The acute versus the chronic response to exercise. Med Sci Sports Exerc. 2001;33:S438-45.

30. Thompson PD, Cullinane E, Henderson LO, Herbert PN. Acute effects of prolonged exercise on serum lipids. Metabolism. 1980;29:662-5.

31. Durstine JL, Miller W, Farrell S, Sherman WM, Ivy JL. Increases in HDLcholesterol and the HDL/LDL cholesterol ratio during prolonged endurance exercise. Metabolism. 1983;32:993-7.

32. Lennon DL, Stratman FW, Shrago E, Nagle FJ, Hanson PG, Madden M, et al. Total cholesterol and HDL-cholesterol changes during acute, moderateintensity exercise in men and women. Metabolism. 1983;32:244-9.

33. Cullinane E, Siconolfi S, Saritelli A, Thompson PD. Acute decrease in serum triglycerides with exercise: is there a threshold for an exercise effect? Metabolism. 1982;31:844-7.

34. Hill S, Bermingham MA, Knight PK. Lipid metabolism in young men after acute resistance exercise at two different intensities. J Sci Med Sport. 2005;8: $441-5$.

35. Taheri Rouhi SZ, Sarker MMR, Rahmat A, Alkahtani SA, Othman F. The effect of pomegranate fresh juice versus pomegranate seed powder on metabolic indices, lipid profile, inflammatory biomarkers, and the histopathology of pancreatic islets of Langerhans in streptozotocin-nicotinamide induced type 2 diabetic Sprague-Dawley rats. BMC Complement Altern Med. 2017;17:156.

36. Wang D, Özen C, Abu-Reidah IM, Chigurupati S, Patra JK, Horbanczuk JO, et al. Vasculoprotective Effects of Pomegranate (Punica granatum L.). Front Pharmacol. 2018;24:544.
37. García-Conesa MT, Chambers K, Combet E, Pinto P, Garcia-Aloy M, AndrésLacueva C, et al. Meta-analysis of the effects of foods and derived products containing Ellagitannins and Anthocyanins on Cardiometabolic biomarkers: analysis of factors influencing variability of the individual responses. Int J Mol Sci. 2018;19:694

38. Sohrab G, Roshan H, Ebrahimof S, Nikpayam O, Sotoudeh G, Siasi F. Effects of pomegranate juice consumption on blood pressure and lipid profile in patients with type 2 diabetes: a single-blind randomized clinical trial. Clin Nutr ESPEN. 2019;29:30-5.

39. Aviram M, Dornfeld L, Kaplan M, Coleman R, Gaitini D, Nitecki S, et al. Pomegranate juice flavonoids inhibit low-density lipoprotein oxidation and cardiovascular diseases: studies in atherosclerotic mice and in humans. Drugs Exp Clin Res. 2002;28:49-62.

40. Vázquez P, Tirado-Cortés A, Álvarez R, Ronjat M, Amaya A, Ortega A. Reversible oxidation of vicinal-thiols motif in sarcoplasmic reticulum calcium regulatory proteins is involved in muscle fatigue mechanism. Cell Calcium. 2016;60(4):245-55.

41. Beck TW. The importance of a priori sample size estimation in strength and conditioning research. J Strength Cond Res. 2013;27:2323-37.

42. Faul F, Erdfelder E, Lang AG, Buchner AG. Power 3: a flexible statistical power analysis program for the social, behavioral, and biomedical sciences. Behav Res Methods. 2017;39:175-91.

43. Beyer KS, Stout JR, Fukuda DH, Jajtner AR, Townsend JR, Church DD, et al, Impact of polyphenol supplementation on acute and chronic response to resistance training. J Strength Cond Res. 2017;31(11):2945-54.

44. Bowtell JL, Aboo-Bakkar Z, Conway ME, Adlam AR, Fulford J. Enhanced taskrelated brain activation and resting perfusion in healthy older adults after chronic blueberry supplementation. Appl Physiol Nutr Metab. 2017;42:7739. https://doi.org/10.1139/apnm-2016-0550.

45. Rinaldi M, Caligiani A, Borgese R, Palla G, Barbanti D, Massini R. The effect of fruit processing and enzymatic treatments on pomegranate juice composition, antioxidant activity and polyphenols content. Food Sci Technol. 2013;53(1):355-9.

46. Zhuang H, Du J, Wang Y. Antioxidant capacity changes of 3 cultivar Chinese pomegranate (Punica granatum L.) juices and corresponding wines. J Food Sci. 2011;76:606-11.

47. Chtourou M, Gargouri B, Jaber H, Bouaziz M. Comparative study of olive quality from Chemlali Sfax Arbequina cultivated in Tunisia. Eur J Lipid Sci. 2013;115:631-40.

48. Dridi-Gargouri O, Kallel-Trabelsi S, Bouaziz M, Abdelhèdi R. Synthesis of 3-Omethylgallic acid a powerful antioxidant by electrochemical conversion of syringic acid. Biochim Biophys Acta. 1830;2013:3643-9.

49. Gargouri B, Ammar S, Zribi A, Ben Mansour A, Bouaziz M. Effect of growing region on quality characteristics and phenolic compounds of chemlali extra-virgin olive oils. Acta Physiol Plant. 2013;35:2801-12.

50. Bougard C, Moussay S, Gauthier A, Espié S, Davenne D. Effects of waking time and breakfast intake prior toevaluation of psychomotor performance in the early morning. Chronobiol Int. 2009;26:324-36.

51. Reilly T, Brooks GA. Investigation of circadianrhythms in metabolic responses to exercise. Ergonomics. 1982;25:1093-7.

52. Matthaiou CM, Goutzourelas N, Stagos D, Sarafoglou E, Jamurtas A, Koulocheri SD, et al. Pomegranate juice consumption increases gsh levels and reduces lipid and protein oxidation in human blood. Food Chem Toxicol. 2014;73:1-6.

53. Hopkins WG, Marshall S, Batterham A, Hanin J. Progressive statistics for studies in sports medicine and exercise science. Med Sci Sport Exerc. 2009; 41:3-13.

54. Bessa AL, Oliveira VN, Agostini GG, Oliveira RJS, Oliveira ACS, White GE, et al. Exercise intensity and recovery: biomarkers of injury, inflammation, and oxidative stress. J Strength Cond Res. 2016;30(2):311-9.

55. Mohr M, Nordsborg N, Nielsen JJ, Pedersen LD, Fischer C, Krustrup P, et al. Potassium kinetics in human muscle interstitium during repeated intense exercise in relation to fatigue. Pflugers Arch. 2004;448(4):452-6.

56. Renaud JM. Modulation of force development by $\mathrm{Na}+, \mathrm{K}+, \mathrm{Na}+\mathrm{K}+$ pump and K ATP channel during muscular activity. Can J Appl Physiol. 2002; 27:296-315.

57. McKelvie RS, Lindinger MI, Heigenhauser GJ, Sutton JR, Jones NL. Renal responses to exercise-induced lactic acidosis. Am J Phys. 1989;257(1 Pt 2): R102-8. 
58. Agrawal V, Agarwal M, Joshi SR, Ghosh AK. Hyponatremia and hypernatremia: disorders of water balance. J Assoc Physicians India. 2008;56: 956-64.

59. Brouns F. Rationale for upper limits of electrolyte replacement during exercise. Int J Sport Nutr. 1992;2:229-38.

60. Boldyrev AA, Bulygina ER. Na/K-ATPase and oxidative stress. Ann N Y Acad Sci. 1997;834:666-8.

61. Boldyrev A, Kurella E. Mechanism of oxidative damage of dog kidney Na/KATPase. Biochem Biophys Res Commun. 1996;222:483-7.

62. Kukreja RC, Weaver AB, Hess ML. Sarcolemmal Na+-K+-ATPase: inactivation by neutrophil-derived free radicals and oxidants. Am J Phys. 1990;259: H1330-6.

63. Wang $Y, X u$ D. Effects of aerobic exercise on lipids and lipoproteins. Lipids Health Dis. 2017;16:132. https://doi.org/10.1186/s12944-017-0515-5.

64. Al-Dujaili E, Smail N. Pomegranate juice intake enhances salivary testosterone levels and improves mood and well being in healthy men and women. End Abstracts. 2012;28:313.

65. Al-Dujaili E, Stockton E. Pomegranate extract intake reduces CVD and diabetes risk factors, stress hormone levels and improves overall quality of life scores in a double-blind, placebo-controlled study. Nutrition. 2014;28(1): 249-2.

66. Esmaillzadeh A, Tahbaz F, Gaieni I, Alavi-Majd H, Azadbakht L. Cholesterol lowering effect of concentrated pomegranate juice consumption in type II diabetic patients with hyperlipidemia. Int J Vitam Nutr Res. 2006;76:147-51.

67. Tsang C, Wood G, Al-Dujaili E. Pomegranate juice consumption influences urinary glucocorticoids, attenuates blood pressure and exercise-induced oxidative stress in healthy volunteers. Endocr Abstr. 2011;25:P139.

68. Trexler ET, Smith-Ryan AE, Melvin MN, Roelofs EJ, Wingfield HL. Effect of pomegranate extract on blood flow and running time to exhaustion. App Physiol Nutr Metab. 2014;39:1038-42.

69. Mazani M, Fard AS, Baghi AN, Nemati A, Mogadam RA. Effect of pomegranate juice supplementation on matrix metalloproteinases 2 and 9 following exhaustive exercise in young healthy males. J Pak Med Assoc. 2014;64:785-90.

70. Cockcroft JR. Exploring vascular benefits of endothelium-derived nitric oxide. Am J Hypertens. 2005;18:177S-83S.

71. Ignarro $L$, Byrns RE, Sumi D, de Nigris F, Napoli C. Pomegranate juice protects nitric oxide against oxidative destruction and enhances the biological actions of nitric oxide. Nitric Oxide. 2006:15:93-102.

72. Hellsten $Y$, Nyberg M, Jensen LG, Mortensen SP. Vasodilator interactions in skeletal muscle blood flow regulation. J Physiol. 2012;590:6297-305.

73. Farràs M, Valls RM, Fernández-Castillejo S, Giralt M, Solà R, Subirana I, et al. Olive oil polyphenols enhance the expression of cholesterol efflux related genes in vivo in humans. A randomized controlled trial. J Nutr Biochem. 2013:24:1334-9.

74. Hernáez Á, Fernández-Castillejo S, Farràs M, Catalán Ú, Subirana I, Montes R, et al. Olive oil polyphenols enhance high-density lipoprotein function in humans: a randomized controlled trial. Arterioscler Thromb Vasc Biol. 2014 34(9):2115-9.

75. Millar CL, Duclos Q, Blesso CN. Effects of dietary flavonoids on reverse cholesterol transport, HDL metabolism, and HDL function. Adv Nutr. 2017; 8(2):226-39

\section{Publisher's Note}

Springer Nature remains neutral with regard to jurisdictional claims in published maps and institutional affiliations.

Ready to submit your research? Choose BMC and benefit from:

- fast, convenient online submission

- thorough peer review by experienced researchers in your field

- rapid publication on acceptance

- support for research data, including large and complex data types

- gold Open Access which fosters wider collaboration and increased citations

- maximum visibility for your research: over $100 \mathrm{M}$ website views per year

At $\mathrm{BMC}$, research is always in progress.

Learn more biomedcentral.com/submissions 